\title{
AN UNUSUAL CASE OF CLOSTRIDIUM WELCHII INFECTION
}

\author{
J. McNae, Keighley, England
}

From the Keighley and District Victoria Hospital, Keighley

Gas gangrene is now a relatively uncommon condition due firstly to a greater appreciation of the need for radical surgical excision of devitalised tissue and secondly to the greatly enhanced efficiency of prophylactic and systemic treatment.

This case appears to be unique for two reasons: firstly, as a confirmed Clostridium Welchii infection of a knee without a penetrating or other injury to the joint and secondly, because the patient regained a full range of knee movement despite considerable internal damage to the joint with massive synovial necrosis.

\section{CASE REPORT}

A woman of forty-eight complained of pain and stiffness in the right knee. Examination revealed a moderate effusion, some tenderness on palpation and painful limitation of both

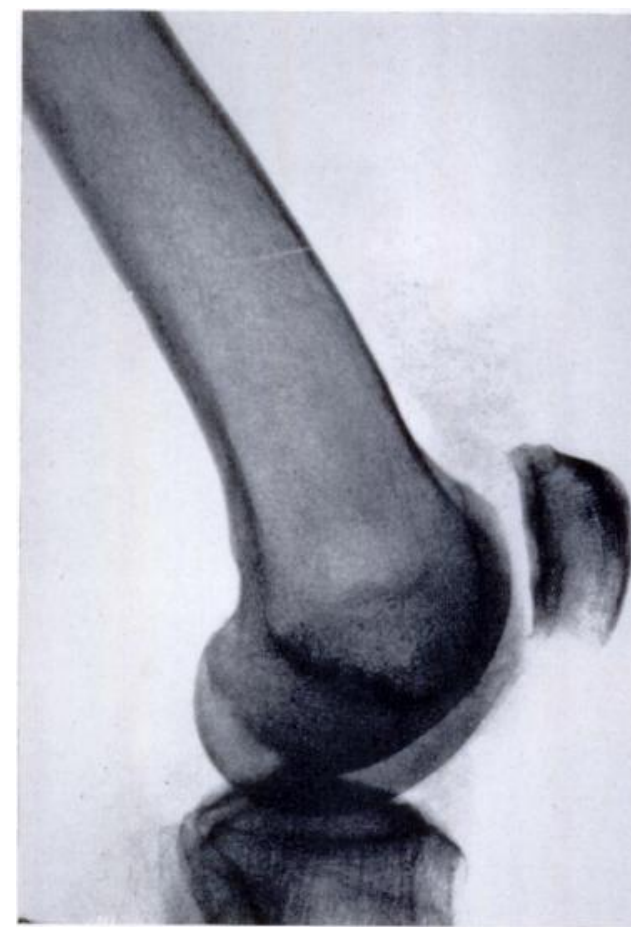

FIG. 1

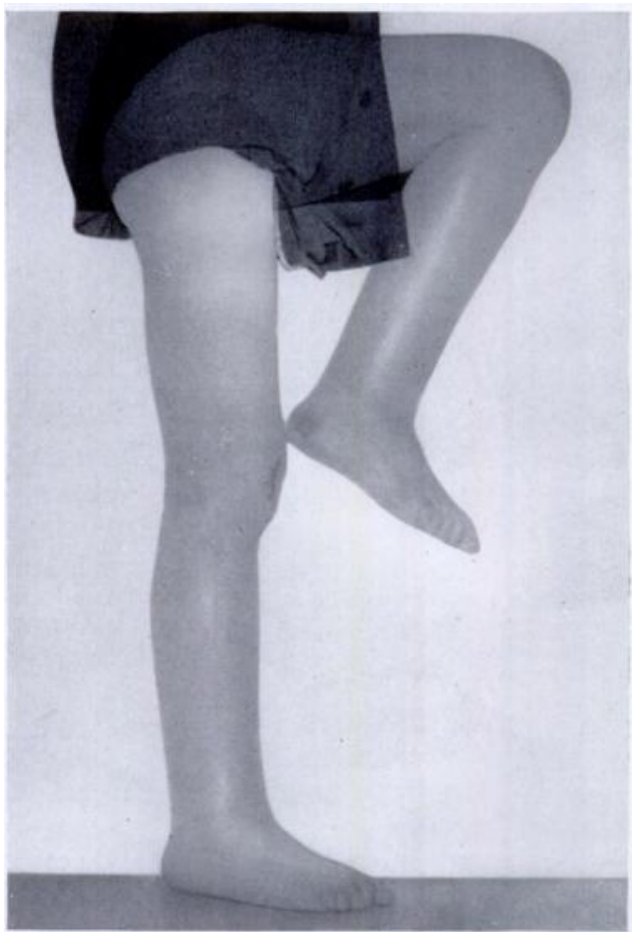

FiG. 2

Figure 1-Radiograph showing gas bubbles in the suprapatellar pouch. Figure 2-Double exposure photograph showing the range of knee movement.

active and passive movement. In spite of systemic Terramycin, the local condition worsened rapidly, and when seen two days later the effusion had increased to massive proportions; tenderness around the joint was extreme, and there was complete absence of movement due to pain. A radiograph of the knee at this stage (Fig. 1) showed bubbles of gas in the suprapatellar bursa. The erythrocyte sedimentation rate was $\mathbf{4 0}$ millimetres in the first hour 
and the white blood cell count was 7,800 per cubic millimetre. A diagnosis of septic arthritis of the knee was confirmed when, on exploration the same day, the joint was found to contain a large quantity of purulent fluid with gross intra-articular inflammatory changes, including extensive necrosis and sloughing of the synovial membrane. All necrotic material was removed as far as possible and the joint was closed after injection of two mega units of crystalline penicillin. A firm compression bandage was applied to the knee and after operation crystalline penicillin, one mega unit six-hourly, was given for five days.

Bacteriological investigation of the pus and necrotic material from the joint revealed large gram positive organisms which were finally and conclusively identified as Clostridium Welchii nine days later. The bacteriologist reported that: "A gram positive bacillus was isolated from a culture obtained in a cooked meat medium. It was proven to be an obligatory anaerobe which gave a positive reaction on a Nagler plate which incorporated Clostridium Welchii type A diagnostic serum. The organism fermented glucose, lactose, maltose and sucrose with the production of gas; it failed to liquefy a coagulated serum slope and gave the typical 'stormy-clot ' reaction with litmus milk medium." As a result of this unexpected finding she was given 20,000 units of gas gangrene serum and was kept in isolation under careful observation, though she was by this time apyrexial and the local condition in the knee appeared to be settling. Her further progress was uncomplicated and she was able to go home three weeks after admission non-weight bearing on crutches with remedial physiotherapy for the knee. Four days later knee flexion was 90 degrees and extension was full. She progressed from partial weight bearing to full weight bearing over the next four weeks. Three weeks after this, when she was discharged from our care, she had almost a full range of knee movement and the quadriceps muscle was as good as the left side (Fig. 2).

\section{COMMENT}

Several points of interest arise. 1) One week before the onset of symptoms in the knee she sustained a minor abrasion above the lateral malleolus on the same leg. This healed normally and showed no signs of infection. 2) She had had diabetes for about eight years, but the disease was well controlled. 3) There was no evidence to indicate the mode of entry of the organism. 4) The recovery of knee movement was very rapid. 5) The culture revealed Clostridium Welchii only.

I wish to make grateful acknowledgment to Professor Robert Roaf for his advice in preparing the paper, also to Dr I. Stewart, Bacteriologist to the Victoria Hospital, Keighley, and to Mr P. Kilburn for his help and his permission to publish the case.

VOL. $48 \mathrm{~B}$, No. 3, AUGUST 1966 